\title{
EMDR-Based Divorce Recovery Group: A Case Study
}

\author{
Sik-Lam Wong \\ Herald Family Rebuilding Center, Fremont, California
}

\begin{abstract}
This case study investigated the effects of an eye movement desensitization and reprocessing (EMDR)based divorce recovery group, consisting of four modalities: (a) modified EMDR Integrative Group Treatment Protocol adapted for adolescents and adults living with ongoing traumatic stress (EMDR-IGTP-OTS) to deal with the trauma from the divorce, (b) modified Affect Circuit Reset protocol to reduce intensity of negative affects, (c) psychoeducation on affects and divorce-related issues, and (d) small group discussion. The divorce recovery program is an attempt to provide an affordable, trauma-focused intervention for divorce recovery for low-income populations. This report summarizes the outcomes in a divorce recovery group of six women, all Chinese immigrants. Aside from one person in the midst of divorce, the group consisted of individuals divorced for 7 years or more, for whom the distress had lasted more than the 2 to 3 years typical of divorce recovery. Short Post-Traumatic Stress Disorder (PTSD) Rating Interview (SPRINT) scores collected at the beginning of week 2 , at the end of week 7 , and at the beginning of week 8 showed PTSD symptoms dropping from severe to mild. The mean SPRINT scores at 6 weeks and 13 weeks after treatment continued to decrease, approaching the no/minimal symptom range. The SPRINT scores showed a $65.6 \%$ reduction between week $2(18.0[S D=8.4])$ and 13 weeks after treatment $(6.2$ $[S D=5.5]$ ), with a large effect size of $d=1.40$, and a significant decrease of $t(4)=4.0, p=.016$.
\end{abstract}

Keywords: eye movement desensitization and reprocessing (EMDR) group; divorce recovery; posttraumatic stress disorder (PTSD); small-t trauma; Affect Circuit Reset; low-income population

D ivorce is considered one of the most traumatic events that can happen to a person (Thomas \& Ryan, 2008). Associated with divorce are strong emotions such as anger, fear, abandonment, and guilt (Lee \& Hett, 1990; Thomas \& Ryan, 2008). There is often confusion and ambivalence, "simultaneously glad to be out of a bad marriage, grieving for the end of the relationship, pining for the ex-spouse, and angry at him or her" (Kitson \& Holmes, 1992, p. 293). At the same time, close to $50 \%$ of the marriages in the United States ended up in divorce between 2000 and 2015 (Centers for Disease Control and Prevention, 2017). While many divorced individuals seek counseling to deal with the turmoil/trauma of their divorce, many others do not have the financial resources for therapy.

This report summarizes the results of an eye movement desensitization and reprocessing (EMDR)-based, trauma-focused, divorce recovery group. The goal of this work is to provide an affordable intervention for low-income clients traumatized by divorce.
Since the rate of divorce in the United States was close to $50 \%$ of marriages for $2000-2015$, this means that more than 1.5 million people per year went through a divorce or annulment during this period.

\section{The Impact of Divorce}

Research has shown that for most people, divorce has a negative effect on psychological health (Hetherington, 2003; Perrig-Chiello, Hutchison, \& Morselli, 2015). For some people, especially those who initiated the divorce and those getting out of abusive relationships, divorce can be positive with increased self-esteem (Amato $\&$ Hohmann-Marriott, 2007; Sakraida, 2005). However, for the majority, the negative effects of divorce, such as unhappiness, distress, depression, alcohol consumption, and health problems, can last 2 to 3 years (Amato, 2000; Hetherington, 2003). Furthermore, for about $10 \%$ to $20 \%$ of divorced individuals, the negative effects continue or even worsen after 10 years (Duffy, Thomas, $\&$ Trayner, 2002; Hetherington, 2003; Perrig-Chiello et al., 2015). Research also suggests that divorce is related to a loss 
of attachment (Akhtar \& Blue, 2017; Davis, Shaver, \& Vernon, 2003; Kitson \& Holmes, 1992; Yárnoz-Yaben, 2010). Divorced individuals are "challenged by the conflicting goals of seeking proximity to the lost attachment figure (i.e., the ex-spouse) and detaching from the ex-spouse" (Akhtar \& Blue, 2017, p. 7). Thus, reducing both positive and negative attachment to the ex-spouse is central to postdivorce adjustment (Tschann, Johnston, \& Wallerstein, 1989; Yárnoz-Yaben, 2010).

Divorce as Trauma. The Diagnostic and Statistical Manual of Mental Disorders (5th ed.; DSM-5; American Psychiatric Association, 2013) criteria for posttraumatic stress disorder (PTSD) require that the disorder is a result of a traumatic or stressful event in which a person's life was threatened or a situation in which a person faced or witnessed physical or sexual violence. Research, however, has shown that non-life-threatening events, such as chronic illness and relational problems, can generate at least as many PTSD symptoms as traumatic events (Mol et al., 2005). Francine Shapiro called such life events "small-t traumas" (Shapiro \& Forrest, 1997, p. 14). While the trauma from life events may not meet the "life-threatening" criterion of DSM- 5 for PTSD, the PTSD symptoms, nonetheless, can be similar to those following a traumatic event, including recurrent thoughts, arousal, negative cognition, and avoidance behavior.

Divorce is a serious relational problem in which the attachment bond between a married couple is broken, and divorced individuals have reported PTSD symptoms of recurrent thoughts, arousal, negative cognition, and avoidance behavior (Arends, 2012). Thus, divorce may be considered as a small-t trauma. From this perspective, trauma-focused approaches such as EMDR may be an effective intervention for divorce recovery.

\section{Effective Treatments for Divorce Recovery}

Various approaches are currently used for divorce recovery. Besides individual therapy, psychoeducation groups and support groups are often used as affordable and effective interventions for divorce recovery.

Group Treatment. Group therapy is a therapeutic intervention beneficial to many people and has been used since the 1950s. A cohesive and supportive group environment can be the safe place where clients can process their own experiences, interact, support, and learn from each other, thus facilitating change and growth (Yalom, 1995). Groups for divorce have been in use as early as the 1970s (Granvold \& Welch, 1979).

Groups can be open-ended, as in many self-help divorce support groups, or they can be brief, lasting only a few sessions. Research has shown that even in a time-limited divorce support group of seven 2-hour sessions, in which the group leader played a relatively passive role, clients reported improvements in their well-being, feeling less depressed and more normal (Øyard, Thuen, \& Solang, 2000).

Psychoeducation. Psychoeducational groups are effective interventions to help clients cope with their mental issues by providing both information and mutual support. Psychoeducational groups have been routinely used in a community setting for helping clients with various mental illnesses such as bipolar disorder and schizophrenia (Colom et al., 2003; Ran et al., 2003).

In the area of divorce, psychoeducational groups are used in school settings for working with children of divorce (Slavkin, 2000). They have also been used with positive results to help divorced parents communicate better with their children (Kanigsberg \& Levant, 1988; McHernry, Clark, \& Stone, 1999). Psychoeducational groups are also effective for divorce recovery, even in a brief therapy format of 8 weeks (Lee $\&$ Hett, 1990). They may offer coping skills to divorced individuals as well as information on the stages of the uncoupling process, providing guidance and support as clients navigate their own recovery. Results from psychoeducational groups have been positive. Clients are able to reduce their anxiety and depression, as well as increase their independence and ability to live in the present rather than dwelling in the past (Lee $\&$ Hett, 1990).

\section{EMDR Therapy}

EMDR therapy was developed by Francine Shapiro $(1995,2001)$ as a psychotherapeutic protocol for dealing with trauma. The efficacy of EMDR for trauma has been well researched in the past two decades and it is accepted as a proven protocol for treatment of PTSD by many U.S. organizations and international agencies (American Psychiatric Association, 2004; Bisson \& Andrew, 2007; Bleich, Kotler, Kutz, \& Shalev, 2002; Chemtob, Tolin, van der Kolk, \& Pitman, 2000; Clinical Resource Efficiency and Support Team, 2003; National Institute for Clinical Excellence, 2005; U.S. Department of Veterans Affairs and Department of Defense, 2004). In addition to successful treatment of PTSD, EMDR therapy has been efficacious for many clients in resolving their small-t traumas (Cvetek, 2008). It has also been integrated with various psychotherapy approaches, such as psychoanalytic, cognitive behavioral, experiential, and marital (Cvetek, 
2008), in which EMDR is used as a tool to deal with targeted traumatic antecedents. Furthermore, EMDR may have the added advantage of bringing faster relief for clients than other treatment protocols (Shapiro, 2014).

EMDR therapy is based on Shapiro's adaptive information processing (AIP) model, which posits that in a normal situation, a person's neurological systems process new information to an adaptive resolution. This means that connections and associations are made in the brain so that "the experience is used constructively by the individual and is integrated into a positive emotional and cognitive schema" (Shapiro, 2001, p. 30). With psychological trauma, the neurological processing may be disrupted so that the experience, including the memory, images, sights and sounds, as well as body sensations, is maintained in an unprocessed state. When the information stays unprocessed, the experience can be triggered by internal and external stimuli, and the individual may reexperience the trauma as flashbacks, nightmares, and intrusive thoughts.

EMDR therapy uses standardized procedures to process such memories and bring resolution. During EMDR treatment, clients recall the disturbing memory in session while simultaneously engaging in eye movements or other bilateral stimulation (BLS), such as alternating taps or tones. At the end of each set of BLS, they report associations and thoughts that were elicited, and this may provide a link between consciousness and the unprocessed trauma memory. The dual attention of the memory and the BLS may facilitate the integration of isolated, unresolved, disturbing memories with current adaptive information to bring the unresolved memory to an adaptive resolution.

EMDR-IGTP-OTS. The EMDR Integrative Group Treatment Protocol (EMDR-IGTP) was developed by the AMAMECRISIS team in response to an overwhelming need for mental health services after Hurricane Pauline in Mexico in 1997 (Jarero, Artigas, López Cano, Mauer, \& Alcalá, 1999). The protocol provides individual EMDR treatment in a group setting. Because this is a group protocol, there are modifications to the eight-phase procedures used in standard EMDR therapy. In a group setting, it is not practical to use eye movements or tappers, and the BLS of choice for the EMDR-IGTP (Artigas \& Jarero, 2014) is the butterfly hug (BH), in which the client crosses her hands across her chest in a hugging gesture and taps below the collarbones, in an alternate fashion (Artigas \& Jarero, 2014). Rather than talking about the targeted trauma and the associated material elicited during processing, clients draw a series of pictures after each set of BLS, rating the subjective units of disturbance (SUD) each time.

The EMDR-IGTP has demonstrated efficacy in symptom reduction even in just one session for children after a critical incident (Jarero, Artigas, Montero, \& Lena, 2008). It has been used to provide mental health services to large and small groups of people in natural and man-made disasters (Jarero, Artigas, Uribe, \& Miranda, 2014). The EMDR-IGTP has also demonstrated efficacy in building resilience for children in an area of ongoing war trauma (Zaghrout-Hodali, Alissa, \& Dodgson, 2008).

Besides natural and man-made disasters, the EMDR-IGTP has also been adapted for adolescents and adults living with ongoing traumatic stress, such as cancer (Jarero et al., 2015; Jarero, Artigas, Uribe, \& García, 2016). The protocol is designated as EMDRIGTP adapted for adolescents and adults living with ongoing traumatic stress (EMDR-IGTP-OTS). This procedure differs from the original in several ways. The EMDR-IGTP is designed for use with a single, critical incident and can be used as a single-session protocol, while the EMDR-IGTP-OTS is designed as a multisession protocol to help clients deal with ongoing traumatic stress. In the EMDR-IGTP, clients are asked to focus on the most disturbing image from the incident. On the other hand, because clients are dealing with ongoing traumatic stress, the EMDRIGTP-OTS asks them to "run the movie of the event" and pick the most disturbing memory at the moment for processing.

\section{Affect Circuit Reset Protocol}

The Affect Circuit Reset (ACR) protocol is a protocol developed by O'Shea (2009) to prepare clients for EMDR therapy. She hypothesized that similar to PTSD in which clients get stuck in a hypervigilant state after a traumatic event, some clients may get stuck in certain emotional states as a result of past traumas. With the ACR, O'Shea theorized that a client, while in a safe state and doing BLS, can reset her emotional circuit to a healthier state. Done prior to EMDR, the ACR may minimize abreactions during processing in session.

In ACR, first, the client learns to put all her traumatic memories into a container. Second, with all her traumatic memories in a container, the client learns to experience a state of feeling safe without the continued presence of those memories. Third, while staying in the safe state and doing BLS, the client 
visualizes various affects one at a time in the following order: shame, fear, anger, grief, seeking, and enjoyment. The client focuses on each affect until the image stops changing, before continuing to the next emotion. If the client feels emotional or has physical sensations, it means that memories are surfacing, and the client puts the memories back into the container before she continues with focusing on the image of the affect.

O'Shea's (2009) ACR protocol is used by many clinicians as a way to prepare traumatized clients for EMDR therapy. However, there has not been any published research on this procedure. On the other hand, research has shown that neuroticism, the stable tendency to react to threat, frustration, and loss with negative affects, such as anger, sadness, anxiety, self-consciousness, and vulnerability, is a robust predictor of many mental and physical disorders (Lahey, 2009). Thus, targeting and processing affects that have been stuck can possibly be a valuable tool for helping clients.

On a related note, research on the working memory model for EMDR has demonstrated that the emotional intensity of a negative memory can be reduced by doing dual attention tasks, that is, holding the memory while doing eye movement, counting, or tapping (Andrade, Kavanagh, \& Baddeley, 1997; Kemps \& Tiggemann, 2007; Maxfield, Melnyk, \& Hayman, 2008; van den Hout, Muris, Salemink, \& Kindt, 2001). Thus, targeting and processing emotions or images/memories of emotions with BLS may be useful in helping clients to reduce the intensity of their emotional response to triggering events.

\section{Treatment Conceptualization}

Divorce is the loss of attachment to a very important person in one's life. A divorced person is often in a highly ambivalent state, wanting to seek proximity to the lost attachment figure and at the same time needing to detach from the ex-spouse (Akhtar \& Blue, 2017). Research by Yárnoz-Yaben (2010) and Tschann et al. (1989) also showed that reducing both positive and negative attachment to the ex-spouse is central to postdivorce adjustment.

From the AIP perspective, the ambivalence and the strong negative emotions suggest that during the divorce recovery period, the divorced person has yet to integrate the experience into "a positive emotional and cognitive schema" (Shapiro, 2001, p. 30). We can thus conjecture that during this time, the person's AIP has been disrupted, similar to the case of a psychological trauma. In other words, we conceptualize divorce as a small-t trauma coming from the loss of attachment to the ex-spouse. From this perspective, trauma processing with EMDR may be beneficial for divorce recovery by forging new connections with adaptive information.

\section{The EMDR-Based Divorce Recovery Treatment Procedure}

In terms of treatment, our goal is to provide an affordable and effective treatment protocol that can bring fast symptom relief to low-income clients traumatized by divorce. Based on our conceptualization of divorce as a small-t trauma as a result of loss of attachment to the ex-spouse, our treatment protocol has the following four modalities.

1. First, the protocol is based on EMDR therapy, a trauma protocol that has demonstrated rapid symptom relief to clients (Shapiro, 2014). We used a modified EMDR-IGTP-OTS group for the processing of traumatic memories.

2. Second, the protocol includes processing of emotions, which may provide fast symptom relief to clients by reducing the intensity of their negative emotions. We used a modified version of ACR and targeted some of the affects.

3. Third, the protocol includes psychoeducation to provide additional, adaptive information to clients.

4. Fourth, on a practical level, the protocol is group based so that it can be affordable to low-income clients. Group therapy also brings in additional benefits of a sense of belonging and not being alone, as well as informal learning and support from other group members.

\section{Modified EMDR-IGTP-OTS}

Our EMDR-based divorce recovery group made some minor modifications to the EMDR-IGTP-OTS, and these are listed in Table 1. Also, we modified the BH procedure, so that instead of crossing the arms and alternately tapping below the collarbone, our participants crossed their arms and alternately tapped on each shoulder.

EMDR-IGTP-OTS was provided to the participants in sessions 2 through 7 (see Table 2). The process began each week by asking participants to run a mental movie of the trauma and identify a target for processing. The participants then drew pictures to represent how they felt about their targets and assigned scores on the SUD scale for their target memories. Focusing on their own target memory and feelings, the participants did four 2-minute periods 


\begin{tabular}{|c|c|c|}
\hline Phase & EMDR-IGTP-OTS Procedures & $\begin{array}{l}\text { Modified EMDR-IGTP-OTS for Divorce } \\
\text { Recovery Group }\end{array}$ \\
\hline 1. History taking & Clinician obtains client history in initial individual session. & No history taking \\
\hline 2. Preparation & $\begin{array}{l}\text { Clinician educates client on the butterfly hug (BH), self- } \\
\text { soothing technique, and procedures for EMDR-IGTP- } \\
\text { OTS. }\end{array}$ & Same \\
\hline 3. Assessment & $\begin{array}{l}\text { Client accesses target by running mental movie and } \\
\text { identifying target for processing. }\end{array}$ & Same \\
\hline 4. Desensitization & $\begin{array}{l}\text { Client processes experience toward an adaptive resolution by } \\
\text { drawing a picture to represent the target experience and } \\
\text { rating the distress on a } 0-10 \text { subjective unit of disturbance } \\
\text { (SUD) scale. Client performs three periods of } \mathrm{BH} 2-3 \\
\text { minutes each and repeats drawings and SUD score for } \\
\text { each period. }\end{array}$ & $\begin{array}{l}\text { Same except client doing four periods of } \\
\text { BH, } 2 \text { minutes each, with picture and } \\
\text { SUD score }\end{array}$ \\
\hline 5. Future vision & $\begin{array}{l}\text { Client draws picture of how she views the future, adds a } \\
\text { sentence or caption, and does } \mathrm{BH} \text {. }\end{array}$ & $\begin{array}{l}\text { Client draws picture of how she views } \\
\text { the future, adds a sentence or caption. } \\
\text { No BH }\end{array}$ \\
\hline 6. Body scan & $\begin{array}{l}\text { Client focuses on the most disturbing drawing, feels body } \\
\text { sensation, and does } \mathrm{BH} \text {. }\end{array}$ & No body scan \\
\hline 7. Closure & $\begin{array}{l}\text { Client ends session with self-soothing exercise and discusses } \\
\text { experience of the session. }\end{array}$ & $\begin{array}{l}\text { Client discusses experience of the } \\
\text { session. }\end{array}$ \\
\hline 8. Reassessment & $\begin{array}{l}\text { Clinician reviews drawings to identify clients needing } \\
\text { attention. Refers clients for individual therapy as needed at } \\
\text { completion of group. }\end{array}$ & Same \\
\hline
\end{tabular}

Note. EMDR-IGTP-OTS = EMDR Integrative Group Treatment Protocol adapted for adolescents and adults living with ongoing traumatic stress.

of $\mathrm{BH}$. At the end of each period, the participants again drew pictures to represent how they felt about their own target memory and assigned SUD scores. After the last period of $\mathrm{BH}$, the participants also drew a picture with a word or caption to represent how they viewed the future. Due to time constraints, we did not do a body scan in our modified EMDRIGTP-OTS protocol. This section ended with some time for participants to discuss their experience with the processing (see Table 1).

\section{Modified ACR Protocol}

We chose to process affects in this therapy group, inspired by O'Shea's ACR protocol (O'Shea, 2009), with the goal of providing fast symptom relief to clients by reducing the intensity of their negative emotions. We followed O'Shea's ACR procedure in sessions 2 and 3. However, instead of focusing on affect, the participants visualized care and play while doing BLS. The procedure stopped when the images stabilized, and there was no further processing with BLS or tracking of SUD scores. The goal of the visualization of care and play was to reset the participants' care and play circuits so that they could be more open to receiving care and seeking enjoyment.

Modified ACR was provided to participants in sessions 4 through 7 . The ACR procedure asks clients to visualize the affect while they are in a stress-free place, and our clients obtained an image of the affect starting from a safe state per the ACR protocol. However, we did not use ACR's technique of placing emotions into a container. We modified the procedure instructing clients to feel the affect, assign a SUD score, and then process the affect while doing $\mathrm{BH}$.

In this segment of our protocol, attendees were asked to sit comfortably in their chairs, close their eyes, and visualize sitting in front of a large-screen TV. They visualized switching to a channel on their remote control named anger or another emotion to be processed. Attendees visualized what came up on the TV and waited until the image stopped changing. They then rated their distress on a SUD scale of 0 to 10 before the processing, based on the image of the particular emotion. Attendees then did four 2-minute periods of $\mathrm{BH}$, while focusing on the image and 


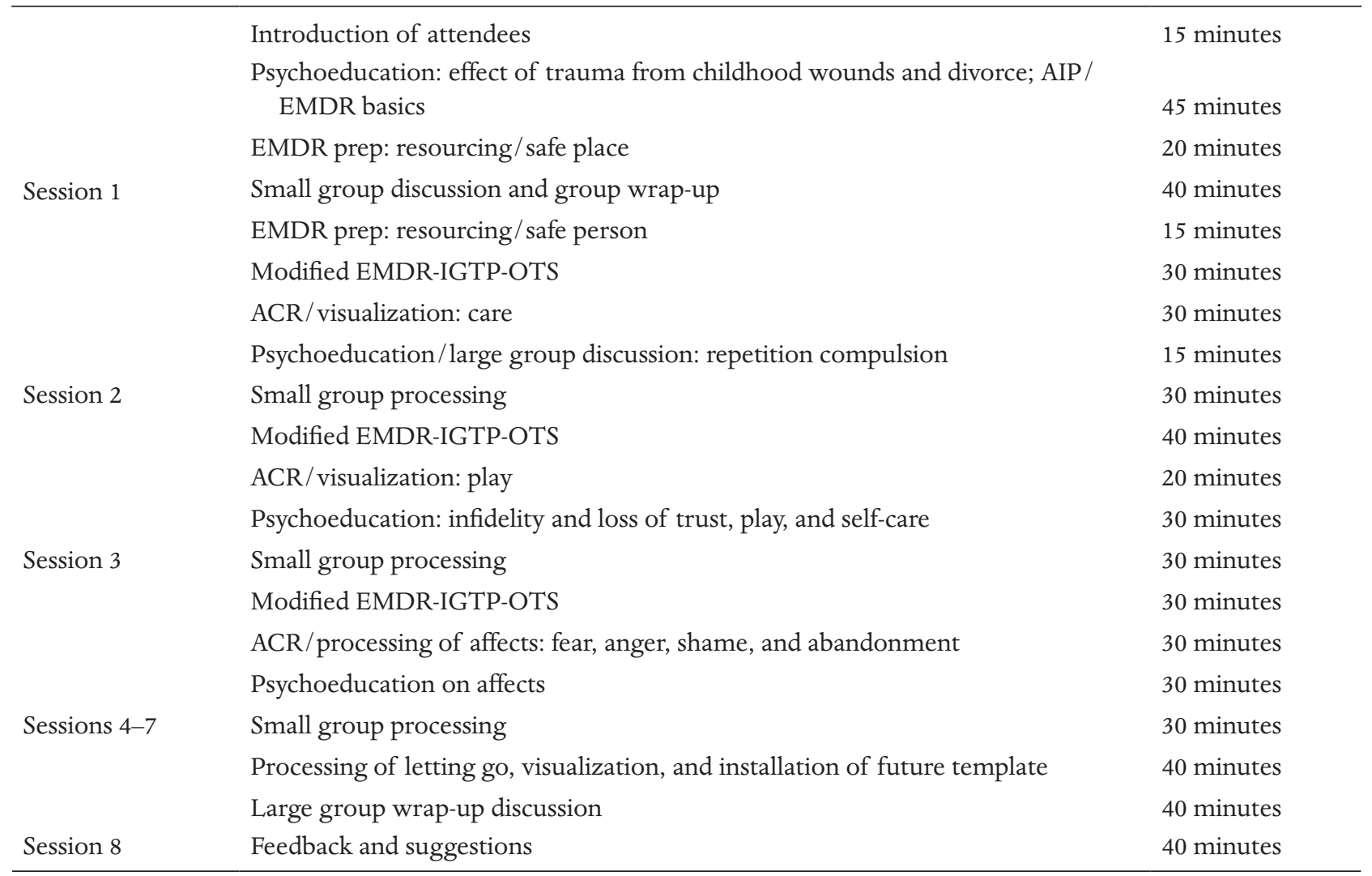

Note. ACR = Affect Circuit Reset; AIP = adaptive information processing; EMDR = eye movement desensitization and reprocessing; EMDR-IGTP-OTS = EMDR Integrative Group Treatment Protocol adapted for adolescents and adults living with ongoing traumatic stress.

emotion, and rated their SUD score at the end of each 2-minute period.

This processing of affects was also based on the working memory model, and we aimed to reduce the emotional intensity of four affects: (a) fear, (b) anger, (c) sense of abandonment, and (d) shame. Reducing the intensity of the four affects may also reduce the negative attachment to the ex-spouse and be helpful for divorce recovery.

There was no processing of affects in session 8 . Instead, we included a "letting go visualization" as an imaginary ritual to let go of unwanted memories and emotions from the past. Each attendee visualized putting her disturbing memories and emotions into a boat and then assigned a SUD rating on how distressing it was for her to let go of those memories and emotions. After that, each attendee did four 2-minute periods of $\mathrm{BH}$, adding more memories and emotions onto the boat if she wanted to, and rated her SUD at the end of each 2-minute period. During the last period, each attendee also visualized the boat drifting down a river and disappearing with her disturbing memories and emotions. Each attendee then drew a picture with a caption to represent her vision of the future. The future vision was installed with 30 seconds of $\mathrm{BH}$. Attendees also shared what they learned and the changes they made during the group. The group ended with attendees giving their suggestions for improvements.

\section{Psychoeducation}

We chose to provide psychoeducation in this group in order to give clients a better understanding of their emotions and how their past traumas might have affected their present divorce recovery process. The psychoeducation covered an overview of EMDR and effects of trauma, including trauma from childhood wounds and trauma from divorce. It included discussions on self-care/play and receiving care. The psychoeducation also included a discussion on affects: fear, anger, abandonment, and shame. The discussion included personal resources/support to deal with fear. It explored some of the underlying issues of the affects: (a) anger as possibly a secondary emotion, (b) sense of abandonment as possibly a need to let go of a broken relationship, and (c) shame as possibly a result of dysfunctional 
internalized rules. The psychoeducation was meant to provide insight and adaptive information, which may enhance the processing of distressing memories and strong affects.

\section{Group Discussion}

Each session concluded with a 30-minute small group discussion of the clients' experience with the EMDR process as well as their insights, issues, and improvements. The attendees were assigned to two small groups of three people, led by two experienced lay counselors. The lay counselors provided empathetic listening as the attendees processed their experience and their issues.

\section{Method}

This EMDR-based divorce recovery group is first and foremost a group to help clients work through the trauma of their divorce. Thus, it was designed to maximize efficacy, using the EMDR-IGTP-OTS, which has a proven history of effectiveness for dealing with trauma. In addition, it attempts to reduce the intensity of the clients' negative emotions, drawing from the ACR protocol and the working memory model. Furthermore, it incorporates psychoeducation and group debriefing and processing, which have been shown to support divorce recovery.

\section{Participants}

This EMDR-based divorce recovery group was held at the Herald Family Rebuilding Center (HFRC), a low-fee counseling center working with Chinese immigrants in Fremont, California. The group was conducted in Mandarin. Clients learned about the group through our advertisement in a local newspaper, through the agency's newsletter, as well as through word of mouth. There was no formal selection process and all applicants were enrolled in the program.

We began with seven divorced women and one woman going through the process of divorce. However, one person dropped out after a few sessions, and the data was based on a group of six people: five already divorced and one undergoing divorce.

The age of the attendees ranged from the mid-40s to the early 70 s. The number of years after divorce ranged from 7 to 30 years. Thus, aside from the one person in the process of her divorce, our attendees fell outside the typical period of 2 to 3 years for divorce recovery (Amato, 2000).

\section{Therapists}

The therapist providing this intervention was the author of this article, who also collected all the data. $\mathrm{He}$ is a Marriage and Family Therapist licensed in California, the United States, and is a certified EMDR therapist. He also holds a doctorate in electrical engineering. The group was supported by two other lay counselors, who were experienced in supportive listening, and they provided quiet, calming support to participants as needed. The therapist and lay counselors were all affiliated with the HFRC in Fremont, California.

\section{Measures}

SUD Score. The SUD scale is used in EMDR treatment sessions to evaluate in-session changes in distress. It is scored on a Likert scale, where $0=$ no disturbance and $10=$ worst imaginable. In the EMDRIGTP-OTS part of the session, the participants were asked to write the SUD score after accessing their target memory and again after each of the four 2-minute periods of BLS. Similarly, in the ACR section of the session, the participants were asked to write the SUD score after accessing an image of the affect to be processed, and again after each of the four 2-minute periods of BLS. Thus, the participants and the therapist could track the change in distress as a result of the processing of the target memory or the affect.

Short PTSD Rating Interview. The instrument used to monitor the progress of our EMDR-based divorce recovery group was the Short Post-Traumatic Stress Disorder (PTSD) Rating Interview (SPRINT), developed by Connor and Davidson (2001). According to the authors, "A score of 18 or above corresponded to marked or severe illness, while a mean score of 17 corresponded to moderate symptoms of PTSD. Scores around 10 corresponded to mild symptoms, and scores of 6 or less indicated either no or minimal symptoms." The SPRINT consists of eight questions with numerical scores, ranging from 1 to 4 , that can be summed to indicate the severity of the PTSD symptoms. There are two more differently scored questions for felt improvements since treatment. In our EMDR-based divorce recovery group, we used the eight numerically scored questions in the SPRINT as an indication for the attendees' self-reported symptom severity.

Clients filled out the SPRINT at the beginning of week 2 prior to the start of EMDR, at the end of week 7 , and again at the start of the group in week 8 . Our past experience with groups was that some clients 


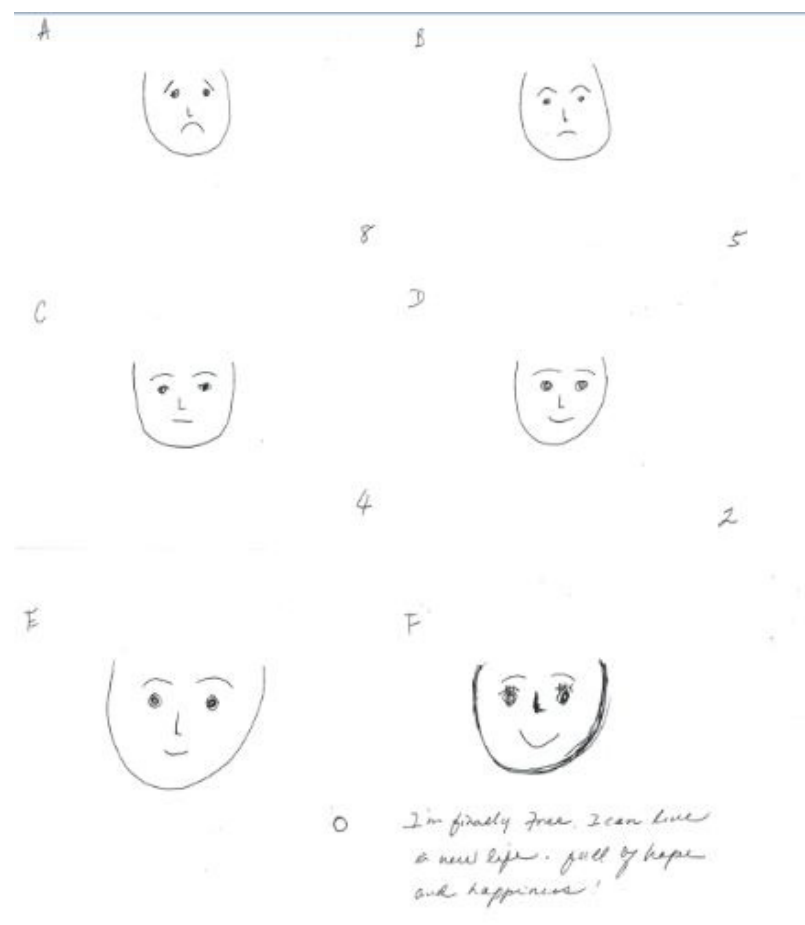

Figure 1. Faces drawn by a client in session 5 during the EMDR-IGTP-OTS process, showing the emotion and SUD scores after each 2-minute period of $\mathrm{BH}$, illustrating the rapid processing of disturbing memory. EMDR-IGTP-OTS $=$ EMDR Integrative Group Treatment Protocol adapted for adolescents and adults living with ongoing traumatic stress.

may skip the last session, and the SPRINT at the end of week 7 was an attempt to have a complete data set near the end of treatment. However, all clients attended the final session.

The SPRINT was mailed to clients at 4 weeks after the group and again at 12 weeks after the conclusion of the group. Clients were asked to fill out and return the surveys as part of ongoing research to track the efficacy of the group protocol. They were reminded via e-mail after the surveys were mailed and encouraged to complete the surveys, but completing the SPRINT after the group was strictly voluntary.

\section{Treatment}

The treatment provided was the EMDR-based divorce recovery group described earlier. It consisted of eight 2-hour sessions. The first session aimed at preparing the group for treatment and the last session focused on preparing the group for termination.

The treatment was designed with a trauma and EMDR focus, augmented by a modified ACR protocol for processing of affects, as well as psychoeducation and group discussion. The plan for each session is summarized in Table 2.

\section{Results}

The progress in the modified EMDR-IGTP-OTS segment of the group was typical of EMDR processing. There was rapid processing of disturbing memories and reduction in stress / emotion during the four 2-minute periods of $\mathrm{BH}$, as shown in Figure 1.

Figure 1 was the drawing done by one client in session 5. The face in Panel A represented how the client felt about the disturbing memory before doing the EMDR-IGTP-OTS, and the number " 8 " was the SUD score on a 0 to 10 scale. Panels B to E represented how the client felt about the memory at the end of each of the four 2-minute periods of $\mathrm{BH}$. Panel F was a representation of the client's view of the future at the end of EMDR in that session.

The ACR/affect processing segment of the group also showed rapid improvements, with substantial reduction in SUD scores after four 2-minute periods of $\mathrm{BH}$. The results of the processing of the four different affects are shown in Table 3. The SUD score for the letting go visualization process in session 8 is also included in Table 3. As can be seen in Table 3, the effect sizes for the pre-post SUD score difference was very large, ranging from $d=4.6$ for the processing

TABLE 3. Mean Pre-Post SUD Scores for Four Affects and Letting Go Visualization

\begin{tabular}{|c|c|c|c|c|}
\hline & \multirow[b]{2}{*}{ Session Number } & \multirow{2}{*}{$\begin{array}{l}\text { Pre-Processing } \\
\text { Mean }(S D)\end{array}$} & \multirow{2}{*}{$\begin{array}{l}\text { Post-Processing } \\
\text { Mean }(S D)\end{array}$} & \multirow{2}{*}{$\begin{array}{l}\text { Effect Size of Pre-Post } \\
\text { Difference }\end{array}$} \\
\hline & & & & \\
\hline Fear & 4 & $9.0(1.4)$ & $2.5(3.1)$ & $d=4.60$ \\
\hline Anger & 5 & $7.8(2.8)$ & 2.0 & $d=2.09$ \\
\hline Abandonment & 6 & $8.0(3.4)$ & $3.5(3.1)$ & $d=1.34$ \\
\hline Shame & 7 & $7.3(2.6)$ & $1.3(2.3)$ & $d=2.32$ \\
\hline Letting go & 8 & $5.3(3.8)$ & $1.5(2.5)$ & $d=1.00$ \\
\hline
\end{tabular}

Note. Processing occurred over four 2-minute periods of butterfly hugs. 
TABLE 4. SPRINT Scores During the Course of Treatment and After Treatment

\begin{tabular}{lccccc}
\hline & $\begin{array}{c}\text { Week 2 of } \\
\text { Treatment }\end{array}$ & $\begin{array}{c}\text { Week 7 of } \\
\text { Treatment }\end{array}$ & $\begin{array}{c}\text { Week 8 of } \\
\text { Treatment }\end{array}$ & $\begin{array}{c}\text { 6 Weeks } \\
\text { After Treatment }\end{array}$ After Treatment \\
\hline Mean & 18.00 & 10.17 & 9.17 & 6.83 & 6.20 \\
Std. dev. & 8.44 & 4.31 & 4.92 & 3.13 & 5.54 \\
95\% confidence interval & $12.92-23.08$ & $5.65-14.69$ & $4.01-14.33$ & $3.55-10.11$ & $0.39-12.01$ \\
Cohen's & & 0.93 & 1.05 & 1.32 & 1.40 \\
\hline
\end{tabular}

Note. SPRINT $=$ Short Post-Traumatic Stress Disorder (PTSD) Rating Interview.

of fear to $d=1.34$ for the processing of the sense of abandonment.

\section{SPRINT Scores}

The overall effect of this EMDR-based divorce recovery group is represented by the SPRINT scores. SPRINT surveys were taken at the beginning of week 2 , at the end of week 7 , at the beginning of week 8 , at 6 weeks after treatment, and at 13-week follow-up. Attendees responded to the 1-month postgroup surveys over a period of 4 weeks and the data point was designated as 6 weeks after treatment. For the 13-week data point, one person did not respond to the survey, and the 13-week data point was the average of five respondents instead of six. Table 4 shows the SPRINT scores during the course of treatment and after treatment. The effect size for the pre-post difference was large, with $d=1.40$, and a significant decrease of $t(4)=4.0, p=.016$. Figure 2 shows the group mean SPRINT scores over time.

\section{Discussion}

The results indicate that the group treatment was helpful to clients in reducing their subjective and affective distress and their traumatic stress. The mean SPRINT score at week 2 was $18.0(S D=8.4)$, indicating that the majority of the group had severe PTSD symptoms. At the end of treatment, the mean SPRINT score had decreased to $10.2(S D=4.3)$ at week 7 and $9.2(S D=4.9)$ at week 8 , indicating that the majority of the group had mild PTSD symptoms toward the end of the group. The SPRINT scores decreased further to $6.8(S D=3.3)$ and $6.2(S D=5.5)$, showing that the majority of the group had minimal or no PTSD symptoms 1.5 to 3 months after treatment. There was a $65.6 \%$ reduction in SPRINT scores between week 2 and the 3-month follow-up, with a large effect size of $d=1.40$.

These results showed features typical of EMDR processing. The drawings from the modified EMDRIGTP-OTS showed rapid processing of disturbing memories similar to other published work, for example, Jarero et al. (2016). The results thus suggested that EMDR was a significant component of our treatment protocol.

The processing of affects with the modified ACR protocol, using BLS, was consistent with the working memory theory. Attendees welcomed the rapid processing of affects, especially the processing

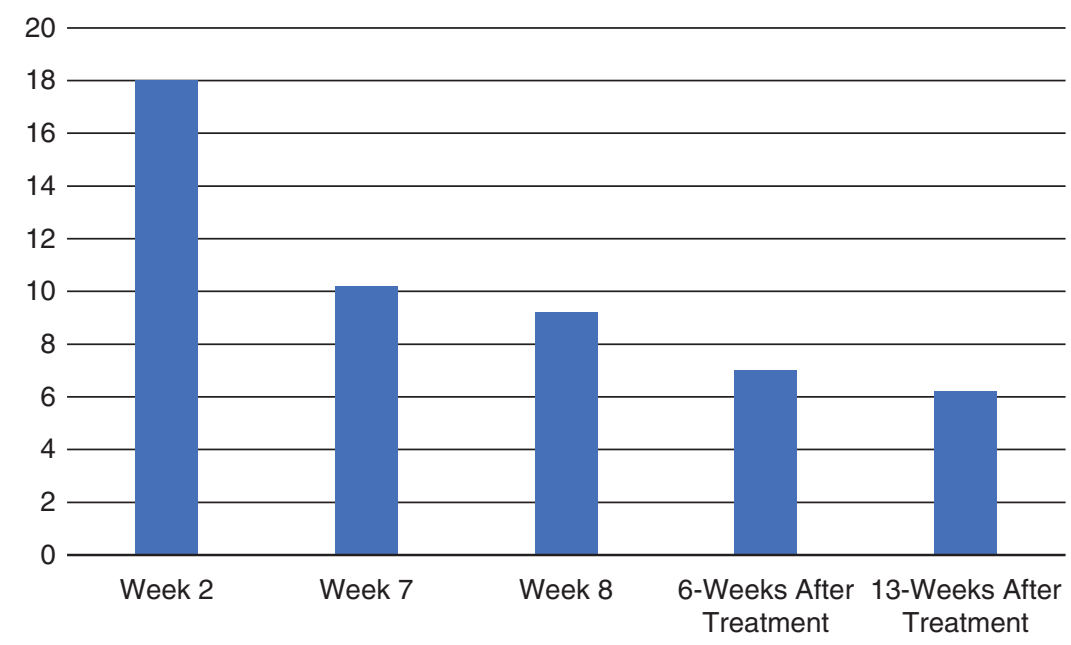

Figure 2. Mean Short Post-Traumatic Stress Disorder (PTSD) Rating Interview scores of the EMDR-based divorce recovery group, showing sustained improvement over time. 
of anger. The following was a comment made by an attendee about processing her anger, translated from Chinese: "At first I imagined shaking him up and slapping him in the face and telling him 'How can you do this to me?' But after a couple of periods of butterfly hugs, the anger dissipated. Towards the end, I was able to let go."

Some participants found it more difficult to process their sense of abandonment and this is indicated in the higher postprocessing mean (3.5) and a smaller effect size $(d=1.34)$, as compared to the other affects (see Table 3). However, as a group, the data showed substantial improvements for all four affects, ranging from $d=4.6$ for fear to $d=1.34$ for sense of abandonment.

This group was meant to provide an economical mode of delivering therapy and there were compromises made in the protocol. By using a group format, the processing for each individual was blind to the therapist, and we could not introduce additional interventions such as cognitive interweaves if a client were to get stuck. On the other hand, the peer learning in a group environment as well as psychoeducation were intended to provide additional adaptive information to aid with the trauma processing with EMDR.

This group was a small step toward a better understanding of an EMDR-based group protocol for dealing with the trauma of divorce. While the results of the group were encouraging, without a direct comparison with another group therapy (e.g., psychoeducation alone) using the same measures, we could not answer the question whether this EMDR-based group was more effective than other existing group protocols.

\section{Adverse Childhood Experience Scores}

At the last session of this group, members completed a 10-question survey of their adverse childhood experiences (ACE; Felitti et al., 1998). An ACE score is a count of the number of types of adverse childhood experiences endorsed by the responder. Research (Felitti et al., 1998) has indicated a dose-response relationship between ACE scores and risks for a variety of physical and mental health problems, that is, higher scores are associated with higher risks. The scores for our participants varied from 0 to 6 with a mean score of 2.7. While every member showed reduction in the SPRINT scores, the two people with the highest ACE scores also showed the least improvement and were referred for more individual work at the completion of the group.
The ACE scores were not needed for this treatment protocol. However, it could be part of patient history in Phase 1 in future groups to identify clients with substantial childhood trauma.

The efficacy of this protocol will be tested as we include more clients with higher ACE scores and higher incidences of childhood abuse or neglect. Correlating the outcome with previous trauma history of the attendees can provide guidance in the limitation of this protocol.

\section{Safety}

Another issue to consider for this EMDR-based protocol is the issue of severe abreaction, for example, having flashbacks or going into dissociation. Working with individuals, clinicians can help clients work through their severe abreaction in session. The question was whether severe abreaction would be an issue with this EMDR-based protocol.

We used the $\mathrm{BH}$ in this group based on the success of the EMDR-IGTP, the predecessor to the EMDRIGTP-OTS. Our clinical judgment was that clients would have control over the BLS and, hence, the process of EMDR, and would slow down or stop the BH and the EMDR without heading into severe abreaction. Attendees might not be able to work through the issues at hand, but the chance of severe abreactions would be low. In addition, some of the leaders in the field have noted that they "have never had a patient leave the group room because they were overly distressed" in the past 20 years of using the EMDR-IGTP protocol with the BH (Jarero et al., 2016, p. 206).

Since BHs have a long safety history for EMDRIGTP groups, we designed this group using $\mathrm{BH}$, and we believed that severe abreaction would not be a problem with our protocol, which was indeed the experience with this group. In addition, besides the lead therapist, the group was supported by two other lay counselors. The lead therapist watched for severe abreactions during the $\mathrm{BH}$, and the lay counselors provided tissues and calming support to individuals if needed. Moreover, the plan was to have those with severe abreactions meet with the lead therapist for individual counseling during the small group time, even though that was not needed in this group.

\section{Conclusions}

Our EMDR-based divorce recovery group was designed as a trauma-focused protocol for divorce recovery. Based on the reduction in SPRINT scores, we concluded that our EMDR-based divorce recovery group was successful in reducing PTSD symptoms in 
our attendees from severe to minimum/no symptoms over time, and the effect may be long-lasting. This protocol may be an effective treatment for processing the trauma of divorce, to be verified by extending this work to large sample sizes in the general population.

Second, this protocol can provide rapid stress relief and processing of traumatic memories, as seen in the attendees' drawings and SUDS during EMDR. This may also suggest that EMDR is a significant component for this protocol. However, with this multimodality protocol, we also expect each modality to contribute to the divorce recovery. As designed, we cannot separate out the contribution of each modality.

Much more research will be needed to fine-tune and streamline this protocol. Our hope is that this group protocol can be the basis of an affordable intervention and be a small step toward filling the gap for mental health needs in the community.

\section{Limitations}

This study has a number of limitations, notably its small sample size, lack of racial and gender diversity, and lack of a control group. Furthermore, with a combination of four different modalities, EMDR-IGTP-OTS, ACR, psychoeducation, and group therapy, one cannot measure the contribution of each modality or whether the same rapid improvements can be achieved without the EMDR-IGTP-OTS and/or the ACR.

Furthermore, there is another limitation in the timing of the baseline SPRINT survey. We had the first survey at the beginning of session 2 . This could have been a confounding factor to the baseline data, as the discussion on family of origin issues could have covertly provided identification of symptoms, which might impact their scoring of the SPRINT. A better baseline measurement would be at the beginning of the first session, prior to commencement of treatment.

Moreover, we might not have fully captured the impact of the treatment since we took the SPRINT surveys before completion of treatment, at weeks 7 and 8 . The survey at week 8 was meant to capture the improvements over the previous 7 weeks of treatment. A better way is to take the SPRINT 1 week after treatment for a better pretreatment and posttreatment comparison.

\section{Future Research}

This EMDR-based divorce recovery group was based on a small sample of six Chinese women. This work will need to be scaled up to larger sample sizes and repeated in the general population to show that the group can be applicable to the general population and the results reproducible. It will also need a control study to demonstrate the effectiveness of this protocol over a control group without therapy.

This EMDR-based divorce recovery group was designed with a trauma focus. It was designed to maximize efficacy by incorporating ACR, psychoeducation, and group therapy. Going forward, we should have a randomized study to explore the effectiveness of this trauma-focused, multimodality protocol relative to psychoeducation and group processing, approaches that are widely used currently.

In addition, given the rapid processing of emotions with $\mathrm{BH}$, we should explore the contribution of the processing of affects as compared to the processing of memories in divorce recovery. Research into whether the processing of emotions can reduce the negative attachment to the ex-spouse may provide new insights for future divorce recovery groups.

\section{REFERENCES}

Akhtar, S., \& Blue, S. (2017). The emotional impact of divorce. In S. Akhtar (Ed.), Divorce: Emotional impact and therapeutic interventions (pp. 1-30). Lanham, MD: Rowman and Littlefield.

Amato, P. R. (2000). The consequences of divorce for adults and children. Journal of Marriage and Family, 62(4), 1269-1287. http://dx.doi.org/10.1111/j.1741-3737. 2000.01269.x

Amato, P. R., \& Hohmann-Marriott, B. (2007). A comparison of high- and low-distress marriages that end in divorce. Journal of Marriage and Family, 69(3), 621-638. http: / / dx.doi.org/10.1111/j.1741-3737.2007.00396.x

American Psychiatric Association. (2004). Practice guidelines for the treatment of patients with acute stress disorder and posttraumatic stress disorder. Washington, DC: Author.

American Psychiatric Association. (2013). Diagnostic and statistical manual of mental disorders (5th ed). Arlington, VA: American Psychiatric Publishing.

Andrade, J., Kavanagh, D., \& Baddeley, A. (1997). Eye-movements and visual imagery: a working memory approach to the treatment of post-traumatic stress disorder. British Journal of Clinical Psychology, 36(2), 209-223. http: / / dx.doi.org/10.1111/j.2044-8260. 1997.tb01408.x

Arends, L. (2012). Lessons from the end of a marriage. Self-published.

Artigas, L., \& Jarero, I. (2014). The butterfly hug. In M. Luber (Ed.), Implementing EMDR early mental health interventions for man-made and natural disasters (pp. 127-130). New York, NY: Springer Publishing.

Bisson, J., \& Andrew, M. (2007). Psychological treatment of post-traumatic stress disorder (PTSD). The Cochrane Database of Systematic Reviews, 2007(3). http://dx.doi. org/10.1002/14651858.CD003388.pub3 
Bleich, A., Kotler, M., Kutz, I., \& Shalev, A. (2002). A position paper of the (Israeli) National Council for Mental Health: Guidelines for the assessment and professional intervention with terror victims in the hospital and in the community. Jerusalem, Israel: Israeli National Council for Mental Health

Clinical Resource Efficiency and Support Team. (2003). The management of post-traumatic stress disorder in adults. Belfast, Ireland: Author.

Centers for Disease Control and Prevention. (2017). National marriage and divorce rate trends. Retrieved from https://www.cdc.gov/nchs/data/dvs/national_ marriage_divorce_rates_00-16.pdf

Chemtob, C. M., Tolin, D. F., van der Kolk, B. A., \& Pitman, R. K. (2000). Eye movement desensitization and reprocessing. In E. B. Foa, T. M. Keane, \& M. J. Friedman (Eds.), Effective treatments for PTSD: Practice guidelines from the International Society for Traumatic Stress Studies (pp. 139-155). New York, NY: Guilford Press.

Colom, F., Vieta, E., Martínez-Arán, A., Reinares, M., Goikolea, J. M., Benabarre, A., . . C Corominas, J. (2003). A randomized trial on the efficacy of group psychoeducation in the prophylaxis of recurrences in bipolar patients whose disease is in remission. Archives of General Psychiatry, 60(4), 402-407. http://dx.doi.org/10.1001/ archpsyc.60.4.402

Connor, K. M., \& Davidson, J. R. (2001). SPRINT: A brief global assessment of post-traumatic stress disorder. International Clinical Psychopharmacology, 16(5), 279-284. http: / / dx.doi.org/ 10.1097 / 00004850-200109000-00005

Cvetek, R. (2008). EMDR treatment of distressful experiences that fail to meet the criteria for PTSD. Journal of EMDR Practice and Research, 2(1), 2-14. http:/ / dx.doi. org/10.1891/1933-3196.2.1.2

Davis, D., Shaver, P. R., \& Vernon, M. L. (2003). Physical, emotional, and behavioral reactions to breaking up: The roles of gender, age, emotional involvement, and attachment style. Personality and Social Psychology Bulletin, 29(7), 871-884. http://dx.doi.org/10.1177/ 0146167203029007006

Duffy, M. E., Thomas, C., \& Trayner, C. (2002). Women's reflections on divorce: 10 years later. Health Care for Women International, 23(6-7), 550-560. http://dx.doi. org/10.1080/07399330290107313

Felitti, V. J., Anda, R. F., Nordenberg, D., Williamson, D. F., Spitz, A. M., Edwards, V., . . . Marks, J. S. (1998). Relationship of childhood abuse and household dysfunction to many of the leading causes of death in adults: The Adverse Childhood Experiences (ACE) Study. American Journal of Preventive Medicine, 14(4), 245-258. http: / / dx. doi.org/10.1016/S0749-3797(98)00017-8

Granvold, D. K., \& Welch, G. J. (1979). Structured, shortterm group treatment of postdivorce adjustment. International Journal of Group Psychotherapy, 29(3), 347-358. http: / / dx.doi.org/10.1080/00207284.1979.11492000

Hetherington, F. M. (2003). Intimate pathways: Changing patterns in close personal relationships across time.
Family Relations, 52(4), 318-331. http://dx.doi.org/10. $1111 /$ j.1741-3729.2003.00318.x

Jarero, I., Artigas, L., López Cano, T., Mauer, M., \& Alcalá, N. (1999). Children's post traumatic stress after natural disasters: Integrative Treatment Protocol. Poster presented at the annual meeting of the International Society for Traumatic Stress Studies, Miami, FL.

Jarero, I., Artigas, L., Montero, M., \& Lena, L. (2008). The EMDR Integrative Group Treatment Protocol: Application with child victims of a mass disaster. Journal of EMDR Practice and Research, 2(2), 97-105. http: / / dx.doi. org/10.1891/1933-3196.2.2.97

Jarero, I., Artigas, L., Uribe, S., \& García, L. E. (2016). The EMDR Integrative Group Treatment Protocol for patients with cancer. Journal of EMDR Practice and Research, 10(3), 199-207. http://dx.doi.org/10.1891/ 1933-3196.10.3.199

Jarero, I., Artigas, L., Uribe, S., García, L. E., Cavazos, M. A., \& Givaudan, M. (2015). Pilot research study on the provision of the eye movement desensitization and reprocessing Integrative Group Treatment Protocol with female cancer patients. Journal of EMDR Practice and Research, 9(2), 98-105. http://dx.doi.org/10.1891/ 1933-3196.9.2.98

Jarero, I., Artigas, L., Uribe, S., \& Miranda, A. (2014). EMDR therapy humanitarian trauma recovery interventions in Latin America and the Caribbean. Journal of EMDR Practice and Research, 8(4), 260-268. http://dx.doi.org/10. 1891/1933-3196.8.4.260

Kanigsberg, J. S., \& Levant, R. F. (1988). Parental attitudes and children's self-concept and behavior following parents' participation in parent training groups. Journal of Community Psychology, 16(2), 152-160. http:/ / dx.doi. org/ 10.1002/ 1520-6629(198804)16:2<152::AID-JCOP22 90160206>3.0.CO;2-R

Kemps, E., \& Tiggemann, M. (2007). Reducing the vividness and emotional impact of distressing autobiographical memories: The importance of modality-specific interference. Memory, 15(4), 412-422. http://dx.doi. org/10.1080/09658210701262017

Kitson, G., \& Holmes, W. (1992). Portrait of divorce. New York, NY: Guilford Press.

Lahey, B. B. (2009). Public health significance of neuroticism. American Psychologist, 64(4), 241-256. http://dx. doi.org/10.1037/a0015309

Lee, J., \& Hett, G. (1990). Post-divorce adjustment: An assessment of a group intervention. Canadian Journal of Counselling, 24(3), 199-209.

Maxfield, L., Melnyk, W. T., \& Hayman, G. C. A. (2008). A working memory explanation for the effects of eye movements in EMDR. Journal of EMDR Practice and Research, 2(4), 247-261. http://dx.doi.org/10.1891/ 1933-3196.2.4.247

McHernry, P., Clark, K., \& Stone, G. (1999). Evaluation of a parent education program for divorcing parents. Family Relationships, 48(2), 129-137. http://dx.doi.org/ $10.2307 / 585076$ 
Mol, S. S., Arntz, A., Metsemakers, J. F., Dinant, G. -J., Vilters-van Montfort, P. A., \& Knottnerus, J. A. (2005). Symptoms of post-traumatic stress disorder after non-traumatic events: Evidence from an open population study. British Journal of Psychiatry, 186, 494-499. http: / / dx.doi.org/10.1192/bjp.186.6.494

National Institute for Clinical Excellence. (2005). Posttraumatic stress disorder: The management of PTSD in adults and children in primary and secondary care. London and Leicester: Royal College of Psychiatrists and British Psychological Society.

O'Shea, K. (2009). EMDR friendly preparation methods for adults and children. In R. Shapiro (Ed.), EMDR solutions II: For depression, eating disorders, performance and more (pp. 289-312). New York, NY: W. W. Norton.

Øyard, L., Thuen, F., \& Solang, P. (2000). An evaluation of divorce support groups: A qualitative approach. Journal of Divorce and Remarriage, 32(3/4), 149-163. http://dx. doi.org/10.1300/J087v32n03_10

Perrig-Chiello, P., Hutchison, S., \& Morselli, D. (2015). Patterns of psychological adaptation to divorce after a long-term marriage. Journal of Social and Personal Relationships, 32(3), 386-405. http://dx.doi.org/10.1177/ 0265407514533769

Ran, M. S., Xiang, M. Z., Chan, C. L., Leff, J., Simpson, P., Huang, M. S., . . . Li, S. G. (2003). Effectiveness of psychoeducational intervention for rural Chinese families experiencing schizophrenia: A randomised controlled trial. Social Psychiatry and Psychiatric Epidemiology, 38(2), 69-75. http://dx.doi.org/10.1007/ s00127-003-0601-Z

Sakraida, T.J.(2005). Divorce transition differences of midlife women. Issues in Mental Health Nursing, 26(2), 225-249. http: / / dx.doi.org/ 10.1080/01612840590901699

Shapiro, F. (1995). Eye movement desensitization and reprocessing: Basic principles, protocols and procedures. New York, NY: Guilford Press.

Shapiro, F. (2001). Eye movement desensitization and reprocessing; Basic principles, protocols, and procedures (2nd ed.). New York: NY: Guilford Press.

Shapiro, F. (2014). The role of eye movement desensitization and reprocessing (EMDR) therapy in medicine: Addressing the psychological and physical symptoms stemming from adverse life experiences. The Permanente Journal, 18(1), 71-77. http://dx.doi.org/10.7812/TPP/ 13-098
Shapiro, F., \& Forrest, M. (1997). EMDR: The breakthrough "eye movement" therapy for overcoming anxiety, stress, and trauma. New York, NY: Basic Books.

Slavkin, M. (2000). The Building Healthy Families Model: Psychoeducational practice with children of divorce. Journal of Divorce \& Remarriage, 32(3/4), 1-17. http:/ / dx.doi.org/10.1300/J087v32n03_01

Thomas, C., \& Ryan, M. (2008). Women's perception of the divorce experience: A qualitative study. Journal of Divorce \& Remarriage, 494(3/4), 210-224. http:// dx.doi.org/10. $1080 / 10502550802222394$

Tschann, J. M., Johnston, J. R., \& Wallerstein, J. S. (1989). Resources, stressors and attachment as predictors of adult adjustment after divorce: A longitudinal study. Journal of Marriage and the Family, 51(4), 1033-1046. http: / / dx.doi.org/10.2307/353214

U.S. Department of Veterans Affairs and Department of Defense. (2004). VA/DoD clinical practice guideline for the management of post-traumatic stress. Washington, DC: Author.

van den Hout, M., Muris, P., Salemink, E., \& Kindt, M. (2001). Autobiographical memories become less vivid and emotional after eye movements. British Journal of Clinical Psychology, 40(2), 121-130. http://dx.doi.org/ $10.1348 / 014466501163571$

Yalom, I. (1995). The theory and practice of group psychotherapy (4th ed.). New York, NY: Basic Books.

Yárnoz-Yaben, S. (2010). Attachment style and adjustment to divorce. The Spanish Journal of Psychology, 13(1), 210219. http: / / dx.doi.org/10.1017/S1138741600003796

Zaghrout-Hodali, M., Alissa, F., \& Dodgson, P. W. (2008). Building resilience and dismantling fear: EMDR group protocol with children in an area of ongoing trauma. Journal of EMDR Practice and Research, 2(2), 106-113. http: / / dx.doi.org/ 10.1891/1933-3196.2.2.106

Acknowledgments. The author benefited from many helpful discussions on this paper with Joy Liu, LMFT. The author also appreciates helpful discussions with Rachel Walker, LMFT, and Charles Wickstrand, LMFT, both EMDRIA- approved consultants, during the preparation of this article.

Correspondence regarding this article should be directed to Sik-Lam Wong, PhD (EECS), Herald Family Rebuilding Center, 917 The Alameda, Berkeley, CA 94707. E-mail: slwmft@gmail.com 